\title{
Investigation on the effect of cold drawing process on mechanical properties and structure of seamless steel (Ck60) tube
}

\author{
Professor Dr. Sorush Niknamian \\ Board Member of Weston A Price Foundation, Washington Dc, USA \\ E-mail: so.niknamian@gmail.com
}

\begin{abstract}
The cold drawing process is one of the precise metal forming techniques which have attracted attention by many researchers with respect to the given properties such as potential for improvement of mechanical properties of the material, achieving of accurate dimensional tolerances and rise of quality at final surface so that different studies are conducted on properties of various materials in the course of analysis of its effect. Using cold drawing and also exertion of special heat treatment cycle in this investigation, initially the seamless steel tube Ck60 has been produced and then effect of cold drawing has been assessed on the mechanical properties and structure of steel. The production process of seamless steel tube includes two phases of cold drawing which was followed by surface reduction levels $15.1 \%$ and $13.7 \%$ respectively. In order to analyze mechanical properties, tensile test and hardnesstesting was used and metallography test was also employed to observe the structure. The given results indicate that the seamless steel tube $\mathrm{Ck} 60$ produced by means of this production process has ultimate tensile strength $(1021 \mathrm{MPa})$, yield strength $(950 \mathrm{MPa})$ and elongation $(9 \%)$. Moreover, the value of hardness mean was 312 for the final tube in Vickers Hardness Test. The images taken from optical microscopy also show that the final structure of tube is uniform and as perlite ferrite.
\end{abstract}

Keywords: Cold drawing-Seamless tube-Mechanical properties- Hardness- StructureHeat treatment 


\section{Introduction}

The history of using of various tubes dated back to several thousand years ago while over the years and following to scientific development and noticeable increase in recognition of materials by human, the kind and method of production of tubes has been changed and improved with respect to the existing requirement. Today, there are several techniques for production of types of tubes but tube production process can be divided into two groups of welded seam tubes produced by welding techniques and those tubes which are manufactured in seamless forms. Inter alia, due to lack of welding seam and having continuous structure, the seamless tubes have greater strength than seamed tubes. Therefore, their unique structure and mechanical properties as well as high speed production has caused this type of tubes to become especially important and to use them widely on various industrial fields such as fluids transition lines at high pressure and operational temperatures, hydraulic circuits, pressured tanks, boilers, automotive industry, various mechanical parts and many other cases $[1,2,3,4]$.

Since time of invention and manufacturing of seamless tubes at the end of nineteenth century, several techniques have been developed for manufacturing of these tubes in parallel with each other among of which there are techniques of centrifugal foundry, rolling by different methods, rotary piercing and cold drawing. Among various techniques and particularly warm forming methods, cold drawing process has some advantages which have caused to attract more attention and to be utilized in different industrial fields. Some of these advantages are the potential to access more precise dimensional tolerances, higher quality of final surface, improvement in some of mechanical properties and potential for production of tube with thinner wall thickness that makes the cold-drawing as distinct from other processes $[2,3,5,6,7,8]$.

The cold drawing process is executed on a hollow initial tube usually using hot rolling or hot extrusion technique to produce final seamless tube with designated properties, quality and dimensional precision. The drawing process of tube is done on a drawing table and during which by drawing of tube from the cast, tube achieves the given diameter and thickness. Drawing is done with/ without using the plug (fixed or floating plug) and by means of mandrel are three general methods for drawing operation. Unlike two other methods, it is also possible to control internal diameter and surface of tube in drawing technique by plug and the internal surface is produced by accurate and finished dimensions. Depending on rate of reduction of given surface, drawing process may be done within several paces. The annealing heat treatment is also executed among any pace of drawing if necessary so that to compensate for hardening caused by the former pace and to prevent from any problem due to redrawing of tube. 
The die and related plug are usually made of tungsten carbide or chromate-coated tool steel [2-11].

Drawing of tube and change in its dimensions by cold drawing process is followed by deformation and subsequently hardening. Therefore, during this process structure of material is changed and affects mechanical and physical properties of material and thus the manufactured end product. On the other hand, with respect to the given endproduct, various heat treatment cycles may be exerted during production process or after the end of drawing on tube. As a result, heat treatment is deemed as a complementary process for cold-drawing. Thus, various studies have been so far conducted on final property and quality of produce tubes with different materials under various parameters of drawing and in different cycles of heat treatment and also now under process of execution.

In their research, Kuroda et al. (2015) examined some of influential factors in dimensional precision of stainless steel tubes treated by cold-drawing. The given results have shown that rising temperature of tool after any drawing phase was the most original factor in changing of final dimensions of drawn tubes. Accordingly, they introduced preheating of tools as a strategy for minimization of changes in final dimensions of drawn tubes [1]. In their experiments Neves et al. (2005) conducted to analyze and reduce tensile force in cold-drawing process of stainless steel tube with the fixed plug, they defined type of lubricant material, lubrication conditions and drawing speed as their variable parameters. The given results showed that using of oil (Extrude-Oil 319 MOS) had the highest effect in reducing of tensile force in mode of lubrication under pressure. It was also observed regarding drawing speed that velocities of 2 and $5 \mathrm{~m} / \mathrm{min}$ would be more suitable for under pressure lubrication as well as reduction in tensile force [8]. Bui et al. (2011) explored effect of level of reduction at cross-section of aluminate tube on the given mechanical properties in cold-drawing process. They showed that rising deformation has increased micro hardness, yield strength and ultimate tensile strength in samples; on the one hand, and reduced correspondent strain to ultimate tensile strength point and elongation, on the other hand [12]. Gattmah et al. (2017) have examined residual stress in cold-drawing process in steel tube (AISI 1010). The results showed that reduction of cross-section highly affected residual stress and tensile forces. They also concluded that plug angle might influence in quantity of residual stress, especially at smaller angles of die [13]. Castro et al (1996) have explored effect of angle of die in mechanical properties of circular annealed copper bars by cold-drawing and observed that with rising die angle, yield strength and ultimate tensile strength were increased and percent of elongation was reduced [14]. A survey was carried out about effect of heat treatment on micro- 
structure and mechanical properties of trip seamless steel tubes by Zhang et al. (2012) and they done tested in order to achieve a suitable composition of strength and ductility, by using different cycles of heat treatment including intercritical annealing and isothermal bainite. By optimization of heat treatment conditions, these persons succeeded in producing of trip seamless steel tube with ultimate tensile strength (542 $\mathrm{MPa}$ ), yield strength (355 MPa) and elongation percent (35\%) [15]. Raji et al. (2012) have tested effect of various times of annealing heat treatment at $900^{\circ} \mathrm{C}$ on mechanical properties of cold-drawn low-carbon steel. Observation of results showed that tensile properties of material were reduced including yield strength and ultimate tensile strength by rising of annealing soaking time. The hardness of material was firstly increased at slow rate during first $30 \mathrm{~min}$ but it was remarkably reduced afterwards and among various times (30-40 min) [16]. Similarly, in another study (2013) the same researchers executed annealing heat treatment under various temperatures and soaking times. They showed that accumulated dislocations in structure of low-carbon steel might remove after cold-drawing process by annealing of them at $650^{\circ} \mathrm{C}$ and soaking time (5-10 $\mathrm{min})$ [17]. Whereas the used heating furnace system in tube production process includes multivariate and nonlinear characteristics thus Xiao et al. (2013) proposed a model to have potential for prediction of final temperature in output tube of furnace [18].

Steel Ck60 (DIN 1.1221) is one of the heat treatable steels which are widely used in manufacturing of different parts such as tubes, wellhead connections, mechanical parts and shafts but no study has been so far conducted on mechanical properties of it after execution of cold-drawing process. The cold-drawing process has been employed along with heat treatment for production in this study to achieve high dimensional precision, improvement of mechanical properties and also creation of a stable and uniform structure in the seamless steel tube. For this purpose, the seamless steel tube is initially produced during two drawing paces and through exertion of unique heat treatment and then the effect of these drawing operations is assessed on the mechanical properties and structure of it by means of metallography, tensile and hardness tests.

\section{Method of test}

\section{1-1 Materials and drawing die}

As it already mentioned, heat-treated steel CK60 (Din 1.1221) has been selected as the given material in this study. To start tube production process, steel (Ck60) billets have been utilized. The quantometric test was conducted on the initial material to ensure from chemical composition of the used material. The quantometric test was implemented by Spark Emission Spectrometer device (made by Spectrolab Company 
of USA) and the given results from this experiment have been shown in Table 1. These results suggest compliance of chemical composition with steel Ck60.

Table 1: Chemical composition of used steel based on weight percent

\begin{tabular}{rcccc}
\hline $\begin{array}{r}\text { Element } \\
\text { Weight }\end{array}$ & $\mathrm{C}$ & $\mathrm{Si}$ & $\mathrm{Mn}$ & $\mathrm{Cr}$ \\
percent & 0.61 & 0.25 & 0.80 & 0.18 \\
\hline $\begin{array}{r}\text { Element } \\
\text { Weight }\end{array}$ & $\mathrm{Mo}$ & $\mathrm{Ni}$ & $\mathrm{P}$ & $\mathrm{S}$ \\
percent & 0.08 & 0.20 & 0.016 & 0.005 \\
\hline Element & $\mathrm{Al}$ & $\mathrm{Co}$ & $\mathrm{Cu}$ & $\mathrm{Fe}$ \\
$\begin{array}{r}\text { Weight } \\
\text { percent }\end{array}$ & 0.19 & 0.01 & 0.16 & Base \\
\hline
\end{tabular}

The initial tube or the mother tube was produced for execution of cold-drawing by conducing of hot rolling process on the steel billet with dimensions $(121 \times 106 \times 7.5 \mathrm{~mm}$ : external diameter $\times$ internal diameter $\times$ thickness) and length of $4.5 \mathrm{~m}$. In this study, two cold-drawn dies with the fixed plug were designed and produced and this was led to reduction of $15.1 \%$ and $13.7 \%$ in the surface of tube at two phases. The tip of die is the foremost part in designing of die that is in contact with external surface of tube and also its main parameters include die drawing angle, radius of die tip entry and bearing length (the forming part of external diameter of tube). The die drawing angle is one of the very influential factors in drawing process and especially in tensile force. Also in order to achieve final smooth surface with high quality, bearing length is determined about three times greater than final thickness of tube. On the other hand, diameter, angle and length of the part in contact with internal surface of tube is very important in relation to design of plug and the given dimensions are determined according to final internal diameter of tube and length of die tip [13]. Dimensions of dies and plugs are calculated with respect to the kind of tube and conditions of cold-drawing process in this test and their main parts along with their dimensions are shown for the first and second phases of drawing in Fig 1 (a) and (b). Both die and plug have been made of tungsten carbide. This material is used for producing of die and plug because it is resistant to high erosion and corrosion in addition to high hardness. 

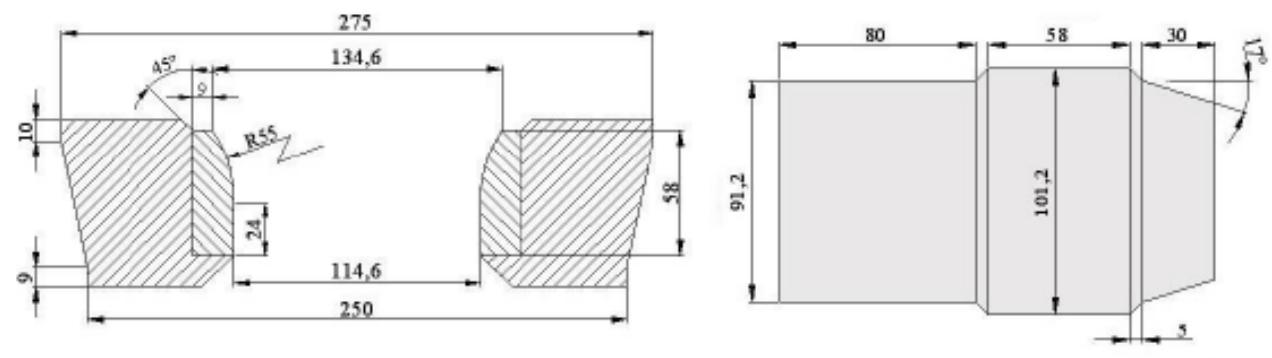

(a)
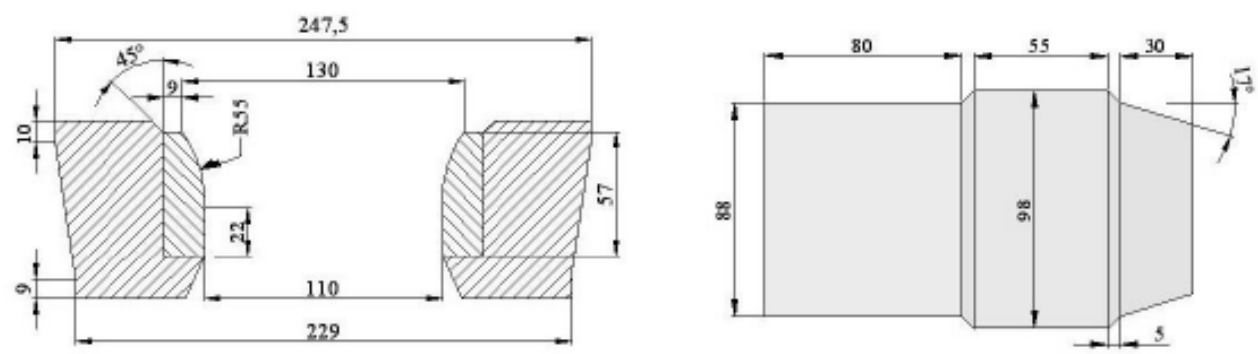

(b)

Fig 1: (a) view of a part of die and plug used at the first drawing phase; (b) View of a part of die and plug used at the second drawing phase

\section{2-2- Cold drawing process of tube}

As it implied in this study, the tubes produced by hot-rolling technique are passed through cold-drawing process from die by the fixed plug in two phases and they reach to external diameter of $110 \mathrm{~mm}$ and thickness $6 \mathrm{~mm}$. In order to analyze structure of the initial tube after hot-rolling process, metallography test has been carried out on it by means of optical microscopy (Metallux model made in Germany). The sample and the etching process have been respectively implemented according to ASTM E3-11 and ASTM E407-07 standards and metallography images were prepared according to ASTM E883-11 standard. The image taken from this test is seen in Fig 2. The results indicate that the initial tube includes bainite structure with some contents of acicular ferrite as well as perlite isles in the background. Therefore it is observed due to the done mechanical work and temperature at the process of production of initial tube, its structure is unstable, non- equilibrium and heterogeneous. 


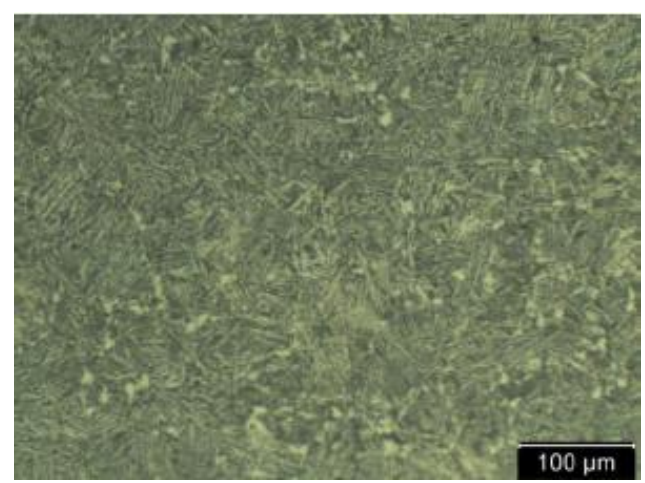

Fig 2: Optical microscopy image from structure of initial tube before heat treatment

\section{2-2-1- Initial heat treatment}

The annealing heat treatment is done on the tube to create uniformity and also to generate a stable perlite structure in the material that is softer than bainite as well before starting of cold-drawing process. After analysis of various backgrounds, cycle of heat treatment has been utilized for the designing test and from continuous furnace R-Feco (made in South Korea) with potential to control atmosphere [19-22]. This furnace includes a thermal part with $12 \mathrm{~m}$ length and a coolant unit (length: $18 \mathrm{~m}$ ). Thermal unit of furnace comprises of five regions per se where in this operation temperature of two first regions is $950^{\circ} \mathrm{C}$ for preheating and temperature in three subsequent regions which includes main temperature has been regulated at $930^{\circ} \mathrm{C}$. The tube moves at fix velocity of $240 \mathrm{~mm} / \mathrm{min}$ and it exits from thermal unit after 50 minutes. Following to passage of water through the designated tubes in body of furnace in coolant unit, the cooling operation is done. The velocity of moving of tube is 550 $\mathrm{mm} / \mathrm{min}$ at this unit and it exits from furnace after 33 minutes.

In order to determine structure of the tube after heat treatment, metallography test was again executed on it with aforesaid equipment and standards. Fig 3 indicates metallography image from the initial tube after heat treatment. As it visible, the tube structure is in perlite form with the contents of ferrite on the background.

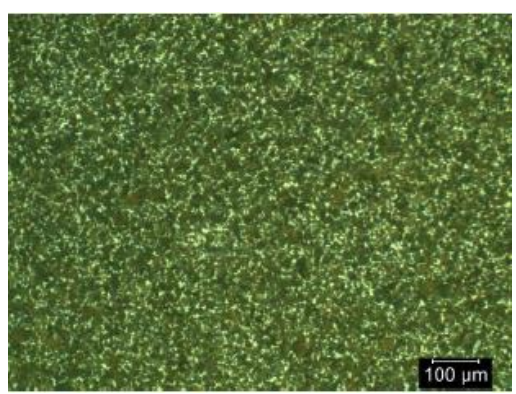


Fig 3: Optical microscopy image from structure of initial tube after heat treatment

\section{2-2-2- Preparation of tube for drawing}

Before starting of drawing process, diameter of initial tube should be reduced at one direction so that the tube can be placed inside drawing die and jaw of drawing device to be locked on it. For this purpose, swaging machine (World Eng made in south Korea) has been used which has execute cold pressing at $30 \mathrm{~cm}$ from the start point of tube by exertion of force ( 350 tons) to reduce the diameter.

To remove pollution and greases which have been so far deposited on the surface of tube, at the next step, the tube is initially degreased and treated by acid-washing. Degreaser (Schiller model) with alkaline compounds has been utilized to remove grease and the tube is passed through a bath with this solution for 20 minutes. Then, the tube is placed again in floating form in a bath with contents of hydrochloric acid $(\mathrm{HCl})$ for acid-washing for 20 minutes. In order to reduce friction between surfaces of the tube and die and for prevention from occurrence of some problems e.g. rupture and tearing before starting of drawing, at the last phase, the tube is initially treated by phosphate and then it is floated in a bath with content of drawing soap at $75^{\circ} \mathrm{C}$ to deposit drawing soap fully on its surface. The tube is treated by phosphate so that drawing soap to be attached well to the surface of it.

\section{2-2-3- Cold drawing}

Drawing process was executed by automatic double-chain drawing table (World Eng made in South Korea) that exerted tensile force amount to 150 tons. The velocity of drawing of tubes is fixed during test and it is $2.6 \mathrm{~m} / \mathrm{min}$. The initial tube is drawing with dimensions of $121 \times 106 \times 7.5 \mathrm{~mm}$ (external diameter $\times$ internal diameter $\times$ thickness) at first phase of drawing and a tube is produced with dimensions of $114.6 \times 101.2 \times 6.7 \mathrm{~mm}$ that amounts to $15.1 \%$ of reduction at the cross-section. Before starting of second-pace of drawing, the tube should be under heat treatment again. To this end, annealing heat treatment is done on the tube according to the cycle already mentioned. Afterwards, chemical operations are executed on tube including degreasing, acid-washing, phosphate treatment, and lubrication with drawing soap as well to prepare it for redrawing. At the second step of drawing that is followed by $13.7 \%$ reduction at cross-section, the tube is drawn again and final tube is produced with dimensions of $110 \times 98 \times 6 \mathrm{~mm}$. After drawing, the tube is passed through a straightener device with ten rollers (made by Poongsan Tech Company of South Korea) and straightened in it. Afterwards, the starting point of tube is cut because of the initial pressing and also $10 \mathrm{~cm}$ at the end of it for reducing of the exerted pressure at the end of drawing. Dimensional tolerance of the produced tube is $0.2 \mathrm{~mm}$ positive 
and $0.1 \mathrm{~mm}$ negative. At the end, eddy-current test has been employed for inspection of defects in the tube and after apparent control.

\section{2-3- Tensile test, hardness testing and metallography}

In order to analyze mechanical properties under various conditions, primarily the initial tube was tested before and after heat treatment and then once-drawn tube and also the final tube was put under tensile test at last. These tests were carried out based on ASTM A370 (2017) and DIN 50125 (2016) and by means of Universal Testing Machine AI-7000LA (made by Gotech Company by Taiwan) with load cell capacity up to $1000 \mathrm{kN}$ and repeated for any sample three times as well. The macro hardness testing was conducted on the initial tube and the final tube by means of Vickers technique and according to ISO 6507-1 (2005) standard and Wolpert device (Germany). In this experiment, the indenter is of diamond pyramid type and force of 10 kg-energy (HV10) was exerted on the sample for 10-15 seconds. Hardness testing was executed in twelve different points of sample and their mean value was expressed as hardness number. Also initial metallographic test was done on the tube that was drawn for once and the final tube.

\section{3- Results and discussion}

\section{3-1- Structure of tube}

As it seen in Fig 2, the produced tube by hot-rolling technique is known as initial tube before heat treatment and it includes non-uniform and unstable and mainly bainite structure. Then execution of heat treatment cycle on that tube changed its structure and led to creation of stable, almost uniform and perlite- ferrite structure in the tube. Figs 4 and 5 show respectively images of optical microscopy from metallographic test on the tube that was drawn in one and two phases. As it observed, the once-drawn tube has mainly perlite structure that is of course followed by contents of grain-boundary ferrite. On the other hand, at this process the exerted tensile force to structure of the tube changes dispersed orientation of the grains before drawing in semi-regular form. Also concerning the final tube which is treated under cold drawing after preparation again, perlite-ferritic structure is seen in the background. Likewise, orientation of the grains has been relatively arranged regularly. Therefore, it can be concluded that execution of heat-treatment cycle on the tube and composing it with the given colddrawing process in this test was led to creation of a uniform, stable and relatively regular perlite-ferritic structure in the tube even after execution of cold-working on it. 


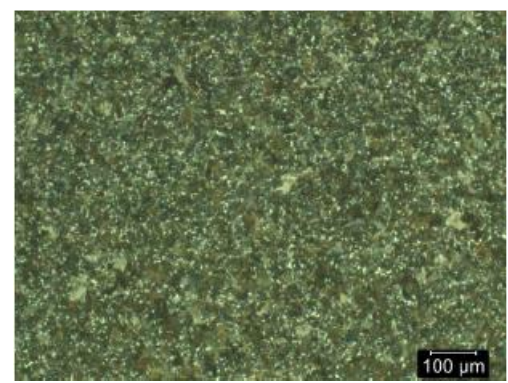

Fig 4: Optical microscopy image from structure of tube after one drawing process

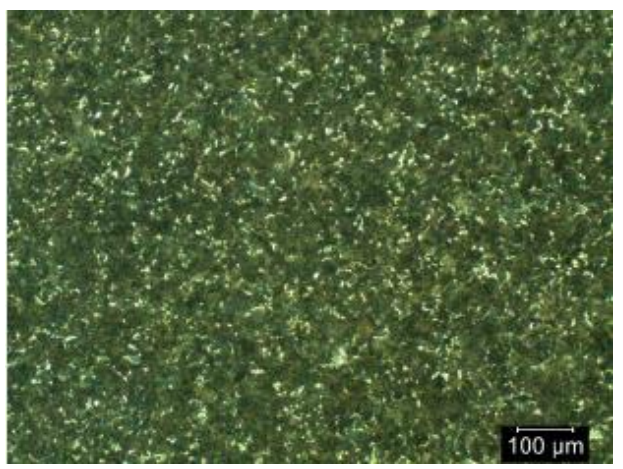

Fig 5: Optical microscopy image from structure of tube after two drawing processes

The quantity of surficial decarburization of the tube was also calibrated during conducting of metallography test. It was visible that there are some traces of partial decarburization with depth of about 208 microns at the surface of initial tube. Decarburization phenomenon takes place as usual when steel is heated up to critical temperature or higher and due to reaction of the existing carbons with atmosphere on the surface of steel [23]. Thus, it can be concluded that the hot-rolling process done on the initial tube is a factor in creation of such decarburization in it. Afterwards, heat treatment of the initial tube acts as a secondary factor and causes creating partial decarburization traces at depth of 331 microns in the external surface of tube and up to 328 microns at the internal surface of it. The final tube has been also analyzed for which the related images are shown in Fig 6. The partial decarburization was observed in this tube up to depth of about 138 microns at the internal surface and in approximately 345 microns at the external surface. 


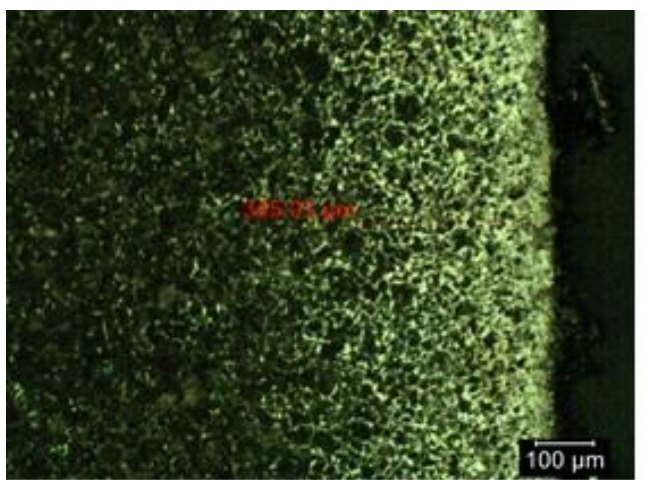

(a)

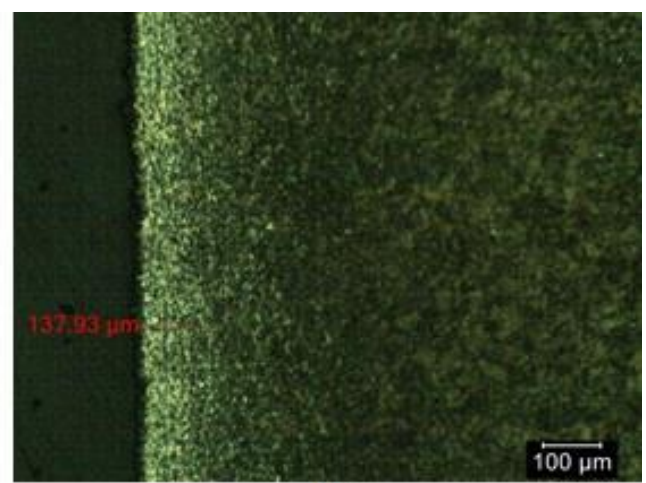

(b)

Fig 6: (a) Decarburization at external surface of the final tube; (b) Decarburization

\section{at internal surface of the final tube}

\section{3-2- Mechanical properties}

The results of tube drawing tests at different phases of study are shown in Table 2. Figs 7 and 8 indicate respectively variances of ultimate tensile strength and yield strength of the steel tube at different test processes and also in Fig 9, strain-stress curve has been compared the initial tube, once-drawn tube and final tube with each other. Review on the given results indicates that the mechanical operation of rolling is primarily done on the steel Ck60 billet to produce the initial tube that caused increase in ultimate tensile strength and related yield strength versus raw steel and reached them to 926 and $772 \mathrm{MPa}$ respectively, but on the other hand the potential was reduced for elongation at $18 \%$. Then, annealing heat treatment has been executed on the initial tube before drawing process to create a uniform and perlite-ferritic structure in it during which structure of the steel became austenitic and then it is cooled within 33 min. This heat treatment causes the structure of steel to become softer than the past by reducing in density of dislocations and regrowth of grains and then ultimate tensile strength and yield strength of the tube is reduced and reach to 835 and $734 \mathrm{MPa}$ respectively. Pursuant to this trend, elongation of the tube is also subsequently followed by $6 \%$ rising and reaches to $24 \%$. Becoming softer and reducing of strength of the tube also increases reduction potential at this level and decreases possibility for occurrence of crack or failure of the tube in drawing by reducing the necessary tensile force. Given these conditions and in order to achieve the aforesaid mechanical properties, cold drawing process is designed and reduction of surface at level of $28.8 \%$ is exerted to the tube within two drawing phases. 
The results derived from the test of tube after first phase of cold drawing suggest rising of strength in the tube and reduction of correspondent strain to ultimate tensile strength so that the ultimate tensile strength is increased up to $977 \mathrm{MPa}$ and yield strength at level of $866 \mathrm{MPa}$ and on the other hand elongation is reduced and reach to $8 \%$. Strength is increased because of cold-working done on the tube that is led to hardening phenomenon and it increases density of dislocations. Therefore, as the piece work is treated under stress and by the increase in density of dislocations, these dislocations act as barriers against way of moving of grains and reduce the potential for their motion. As a result, following to rising of strength, strain is reduced correspondently to the exerted stress and elongation of the tube is decreased. After the second phase of tube cold-drawing, the conducted tensile test on the final tube indicates ultimate tensile strength and yield strength as 1021 and $950 \mathrm{MPa}$ respectively. Thus, it is seen that following to redrawing of the tube, ultimate tensile strength is increased about $4.5 \%$ and also yield strength is increased $7.2 \%$ compared to the once-drawn tube. On the other hand, however the correspondent strain to ultimate tensile strength point is increased so that by $1 \%$ growth, the percent of elongation of the tube reaches to about $9 \%$. Toughness of material, which is also related to the surface area under strain-stress curve, increased as well. The reason for rise of quantity of correspondent strain to exerted stress is latent in the heat treatment between two processes of drawing. Before the first drawing step, heat treatment is done on the initial tube that has mainly Bainite structure, while the tube which is under heat treatment operation before the second process of drawing, has perlite-ferritic structure. Therefore, growth trend of the grains in the second cycle is led to increase percent of elongation or pre-failure strain potential for the twice-drawn tube. Finally, it can be expressed during the second step of colddrawing process, percent of elongation is also slightly increased in addition to the strength of tube and this is positive point.

Hardness of surface in different pieces is considered as one of the important parameters in the end product. Therefore, macro hardness testing has been executed on the initial and final tubes in this study and the mean values of hardness quantity has been derived for them 274 and 312 (HV) based on the Vickers hardness test. Based on the given results, it can be implied that the conducted process in this test increases the surficial hardness of tube about $24.8 \%$ (previously it was about 250 Vickers for initial steel Ck60) in addition to the rise of tube strength. 
Table 2: The given results from the tensile tests

\begin{tabular}{llll}
\hline Tested piece work & $\begin{array}{l}\text { Yield } \\
\text { strength } \\
(\mathrm{MPa})\end{array}$ & $\begin{array}{l}\text { Ultimate } \\
\text { tensile } \\
\text { strength } \\
(\mathrm{MPa})\end{array}$ & $\begin{array}{l}\text { Elongation } \\
(\%)\end{array}$ \\
\hline $\begin{array}{l}\text { Initial tube before } \\
\text { heat treatment }\end{array}$ & 772 & 926 & 18 \\
\hline $\begin{array}{l}\text { Initial tube after } \\
\text { heat treatment }\end{array}$ & 734 & 835 & 24 \\
\hline $\begin{array}{l}\text { Once-drawn tube } \\
\text { Final tube (twice- }\end{array}$ & 950 & 976 & 8 \\
\hline drawn) & & 1021 & 9 \\
\hline
\end{tabular}

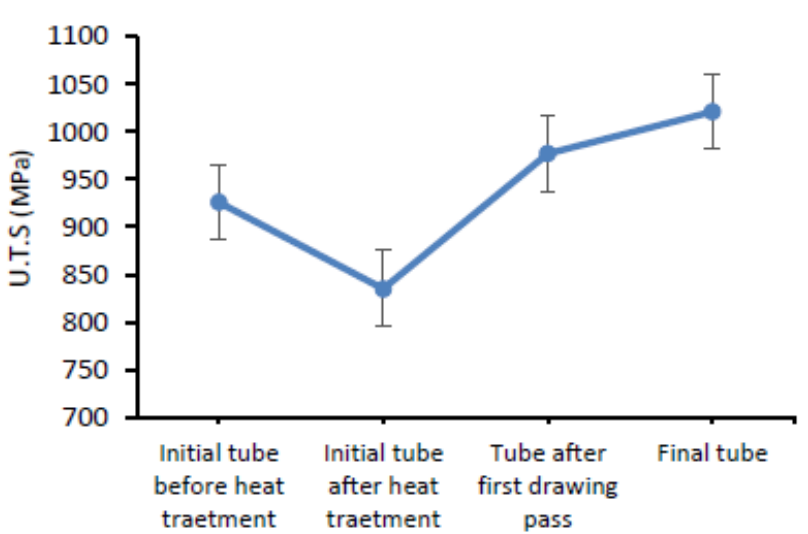

Fig 7: Variance of ultimate tensile strength in the various testing processes 


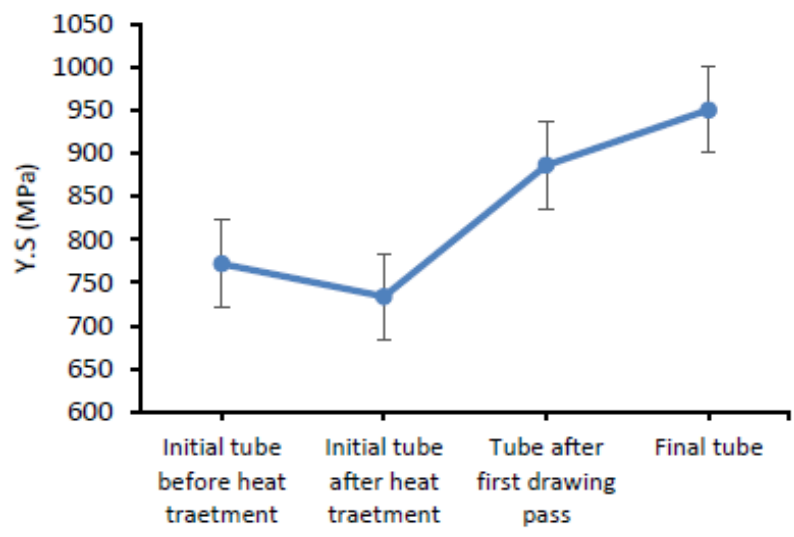

Fig 8: Variance of yield strength in the various testing processes

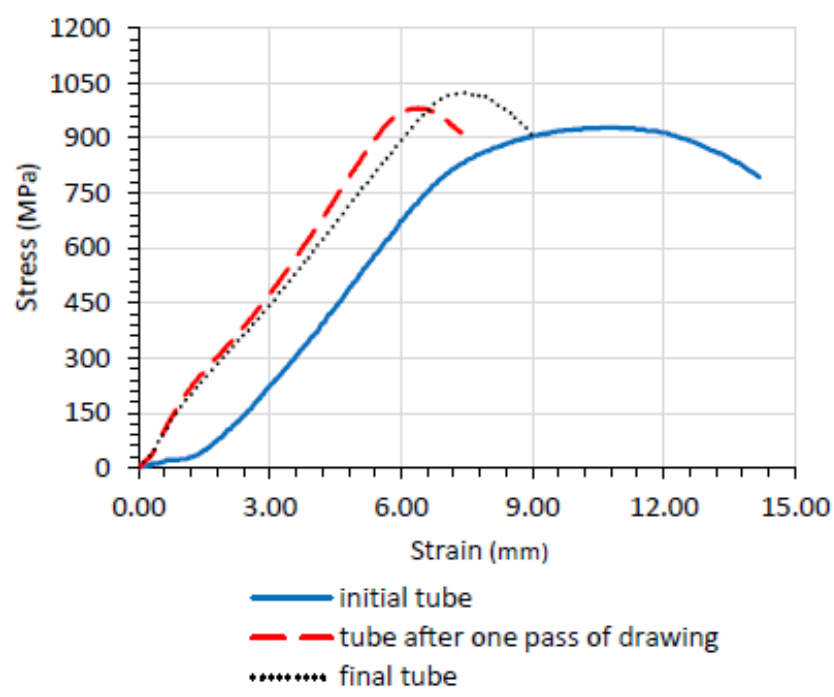

Fig 9: Comparison of strain-stress curve for the initial tube, once-drawn tube and final tube

\section{4- Conclusion}

In order to produce seamless steel Ck60 tube with high strength and a stable and equilibrant structure in this study, the initial tube produced by hot-rolling is primarily treated at two cold drawing processes and the given seamless tube was produced with favorable dimensional precision. Then, effect of cold-drawing process was analyzed on the mechanical properties and steel structure of tube and finally following results were given. 
Execution of the given heat treatment in this test has caused changing of heterogeneous and non-equilibrant structure of the initial tube which included bainite, ferrite and perlite so that the final tube possesses a uniform and stable perlite-ferritic structure with relatively regular grain orientation. The created decarburization is also partial on the surface of tube and depth of its layer is 345 and 138 microns at the external and internal surfaces of final tube respectively.

The cold-drawing increased ultimate tensile strength, yield strength and surficial hardness of the tube and on the other hand correspondent strain with the point of ultimate tensile strength and elongation is reduced in it. The given results indicate that at the first phase of cold-drawing process, the amounts of ultimate tensile strength and yield strength of the tube are increased 17 and $20.7 \%$ respectively and elongation is also reduced $16 \%$. In addition, it was characterized that after the second process of tube drawing, following to the repeated rising in ultimate tensile strength and yield strength of the tube for about 4.5 and $7.2 \%$ respectively, the quantity of elongation was also increased about 1\%. The surficial hardness of final tube was also measured 312 Vickers.

According to the designated production process in this study, the seamless steel (Ck60) tube was achieved successfully with ultimate tensile strength (1021 MPa), yield strength $(950 \mathrm{MPa})$ and elongation of $9 \%$.

\section{References}

[1] K. Kuroda, T. Kawakami, T. Okui, M. Akiyama, M. Kiuchi, Influential factor to dimensional precision of cold-drawn tubes, Pros IMechE Part B: Journal of Engineering Manufacture, Vol. 229, Issue 1, pp. 100-109, 2015.

[2] K. H. Brensing, B. Sommer, Steel tube and pipe manufacturing processes (http://allaboutmetallurgy.com/wp/wp-content/uploads/2016/12/steel_tube_and_pipe.pdf).

[3] P. K. Loharkar, M. K. Pradhan, Handbook of research on manufacturing process modeling and optimization strategies, Vol. 1, pp. 40-53, Hershey: IGI Global Publications, 2017.

[4] K. Kondo, Y. Okada, S. Tanimoto, Method and facility for manufacturing seamless steel pipe, U.S. Patent 5873960A, 1999.

[5] B. S. Rajput, R. Victor, Study of Different Parameters in Seamless Cold Drawing Process Using Finite Element Simulation, International Journal of Engineering Sciences \& Research Technology (IJESRT), Vol. 3, No. 10, pp. 437-446, 2014.

[6] P. Karnezis, D. C. J. Farrugia, Study of cold tube drawing by finite-element modeling, Journal of Materials Processing Technology, Vol. 80-81, pp. 690-694, 1998.

[7] P. Kumar, G. Agnihotri, Cold drawing process -A Review, International Journal of Engineering Research and Applications (IJERA), Vol. 3, Issue 3, pp. 988-994, 2013. 
[8] F. O. Neves, S. T. Button, C. Caminaga, F. C. Gentile, Numerical and experimental analysis of tube drawing with fixed plug, Journal of the Brazilian Society of Mechanical Sciences and Engineering, Vol. 27, No. 4, pp. 426-431, 2005.

[9] M. Siddique, I. M. Cole, Development of tube drawing schedules in a cold drawing plant using expert system technique, Journal of Materials Processing Technology, Vol. 24, pp. 485494, 1990.

[10] L. Shaheen, Cold drawing principles, The Tube and Pipe Journal, June 2010.

[11] H. Palkowski, S. Bruck, T. Pirling, A. Carrado, Investigation on the residual stress state of drawn tubes by numerical simulation and neutron diffraction analysis, Materials Journal, Vol. 6, No. 11, pp. 5118-5130, 2013.

[12] Q. H. Bui, R. Bihamta, M. Guillot, A. Rahem, M. Fafard, Effect of cross section reduction on the mechanical properties of aluminium tubes drawn with variable wall thickness, Journal of Manufacturing Science and Engineering, Vol. 133, No. 6, 2011.

[13] J. Gattmah, F. Ozturk, S. Orhan, Experimental and finite element analysis of residual stresses in cold tube drawing process with a fixed mandrel for AISI 1010 steel tube, The International Journal of Advanced Manufacturing Technology, Vol. 93, Issue 1-4, pp. 12291241, 2017.

[14] A. L. R. de Castro, H. B. Campos, P. R. Cetlin, Influence of die semi-angle on mechanical properties of single and multiple pass drawn copper, Journal of Materials Processing Technology, Vol. 60, Issue 1-4, pp. 179-182, 1996.

[15] Z. Zhang, Y. Li, K. Manabe, F. Zhu, Effect of heat treatment on microstructure and mechanical properties of TRIP seamless steel tube, Materials Transactions Journal, Vol. 53, Issue 5, pp. 833-837, 2012.

[16] N. A. Raji, O. O. Oluwole, Effect of soaking time on the mechanical properties of annealed cold-drawn low carbon steel, Materials Sciences and Applications Journal, Vol. 3, No. 8, pp. 513-518, 2012.

[17] N. A. Raji, O. O. Oluwole, Recrystallization kinetics and microstructure evolution of annealed cold-drawn low-carbon steel, Journal of Crystallization Process and Technology, Vol. 3, No. 4, pp. 163-169, 2013.

[18] D. Xiao, S. Shi, Z. Mao, J. Wang, Modeling and control for the tube blank heating quality of seamless tube, in $9^{\text {th }}$ Asian Control Conference (ASCC), Istanbul, Turkey, pp. 1-5, 2013.

[19] G. E. Totten, Steel heat treatment handbook: Metallurgy and Technologies, Second Edition, Boca Raton: CRC Press, 2006.

[20] Heat treating data E-Book, Tenth Edition, Meadville: Published by SECO/Warwick Corporation, 2011.

[21] A. Kamyabi-Gol, M. Sheikh-Amiri, Spheroidizing kinetics and optimization of heat treatment parameters in CK60 steel using taguchi robust design, Journal of Iron and Steel Research, Vol. 17, Issue 4, pp. 45-52, 2010.

[22] B. S. Motagi, R. Bhosle, Effect of heat treatment on microstructure and mechanical properties of medium carbon steel, International Journal of Engineering Research and Development, Vol. 2, Issue 1, pp. 7-13, 2012.

[23] G. F. V. Voort, Understanding and measuring decarburization, Advanced Materials and Processes, Vol. 173, No. 2, pp. 22-27, 2015. 
